\title{
Successful treatment of severe electrolyte imbalance-induced cardiac arrest caused by adrenal tuberculosis with ECMO in the ED
}

\author{
Ning Yang ${ }^{*}$, Liping Zhou, Xiaoye Mo, Guoqing Huang and Ping Wu
}

\begin{abstract}
Background: Tuberculosis (TB) is a chronic infectious disease, common in China. TB bacteria can invade multiple organs throughout the body, but they rarely cause critical illness. We present a complex critically ill case in this report.

Case presentation: A 40-year-old man suffered sudden cardiac arrest during an emergency room visit. Spontaneous circulation resumed after emergency cardiopulmonary resuscitation (CPR), but recurrent ventricular fibrillation and refractory cardiac shock emerged. Thereafter, extracorporeal membrane oxygenation (ECMO) was implemented to maintain hemodynamic stability. Blood test results revealed that the patient had severe electrolyte imbalance and adrenal insufficiency. Further imaging examination showed multiple tuberculosis lesions throughout the body, including the lungs, adrenal glands, and lumbar spine. In the end, the patient was successfully moved from the ICU after weaning from ECMO and the ventilator, and then transferred to an infectious disease specialist hospital for standard anti-tuberculosis therapy.
\end{abstract}

Conclusions: ECMO has won the opportunity for the diagnosis and treatment of this young patient who suffered from a rare cause of cardiac arrest and finally achieved a good prognosis.

Keywords: Cardiac arrest, Adrenal tuberculosis, Extracorporeal membrane oxygenation

\section{Background}

Patients with various causes of cardiac arrest (CA) are often encountered in the emergency department, and the success rate of treatment for CA is not very high, especially the success rate of cerebral resuscitation is not high. The case report presents a complex critically ill case. A patient with CA caused by rare cause has been successfully treated with severe technology such as extracorporeal life support.

\footnotetext{
*Correspondence: yangningok@csu.edu.cn
}

Department of Emergency Medicine, Xiangya Hospital, Central South University, 87 Xiangya Road, Changsha 410008, Hunan, China

\section{Case presentation}

A 40-year-old man presented to the emergency department (ED) of the local hospital at approximately 11 am due to severe nausea, vomiting, and fatigue. He suddenly fell to the ground and lost consciousness while waiting. The on-site medical staff immediately determined cardiac arrest and performed CPR, defibrillation, and intubation. The patient's spontaneous circulation resumed after approximately $4 \mathrm{~min}$, but he had recurrent ventricular fibrillation and low blood pressure which required high doses of vasoactive drugs (norepinephrine $4 \mu \mathrm{g} / \mathrm{kg} / \mathrm{min}$, terlipressin $1 \mathrm{mg}$ iv $\mathrm{q} 4 \mathrm{~h}$ ). His vital signs were not stable and his condition deteriorated because of increased blood lactate $(3.2 \mathrm{mmol} / \mathrm{l} \uparrow)$ and poor tissue perfusion. The ECMO team was urgently called to the ED to initiate VA-ECMO for the patient, after which he

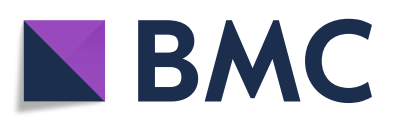

(c) The Author(s). 2021 Open Access This article is licensed under a Creative Commons Attribution 4.0 International License, which permits use, sharing, adaptation, distribution and reproduction in any medium or format, as long as you give appropriate credit to the original author(s) and the source, provide a link to the Creative Commons licence, and indicate if changes were made. The images or other third party material in this article are included in the article's Creative Commons licence, unless indicated otherwise in a credit line to the material. If material is not included in the article's Creative Commons licence and your intended use is not permitted by statutory regulation or exceeds the permitted use, you will need to obtain permission directly from the copyright holder. To view a copy of this licence, visit http://creativecommons.org/licenses/by/4.0/ The Creative Commons Public Domain Dedication waiver (http://creativecommons.org/publicdomain/zero/1.0/) applies to the data made available in this article, unless otherwise stated in a credit line to the data. 
was transferred to the emergency ICU of a tertiary comprehensive hospital.

The family members of the patient reported that the patient had experienced nausea, vomiting, loss of appetite, and fatigue in the past 6 months. He had taken some Chinese herbs for 2 months, but his condition did not improve. He had lost approximately $10 \mathrm{~kg}$ in weight since the onset of illness. The test results in the ED showed blood serum potassium $6.97 \mathrm{mmol} / \mathrm{l}$, blood serum sodium $100.9 \mathrm{mmol} / \mathrm{l}$, and blood serum chlorine $74.1 \mathrm{mmol} / \mathrm{l}$. Blood hormone levels during hospitalization were cortisol $2.3 \mu \mathrm{g} / \mathrm{dl} \downarrow(8 \mathrm{am}), \quad 2.5 \mu \mathrm{g} /$ $\mathrm{dl} \downarrow(4 \mathrm{pm}), \quad 2.7 \mu \mathrm{g} / \mathrm{dl} \downarrow(0 \mathrm{am}), \quad$ adrenocorticotropin (ACTH) $243.7 \mathrm{pmol} / \mathrm{l} \uparrow(8 \mathrm{am}), \quad 270.1 \mathrm{pmol} / \mathrm{l} \uparrow(4 \mathrm{pm})$, $216.2 \mathrm{pmol} / \mathrm{l} \uparrow(0 \mathrm{am})$, blood aldosterone (ALD) $12 \mathrm{pg} /$ $\mathrm{ml} \downarrow$, and renin $(\mathrm{DRC})>500 \mu \mathrm{IU} / \mathrm{ml} \uparrow$. Tuberculosisrelated test results a positive Mycobacterium tuberculosis conformity group (MTB) DNA test, a positive rifampicin resistance (Rif Resistance) gene test, and a positive $\mathrm{T}$ SPOT test (stimulation level > 10, positive level 5.87, and background level 0.07 ). After ECMO and artificial ventilation were discontinued, imaging examination of the patient revealed multiple plaques and nodules in both lungs, multiple nodules in both adrenal glands, bone destruction of the second and third lumbar vertebrae, calcification of paravertebral soft tissue, and a mass lump in the right psoas muscle, suggesting the possibility of tuberculosis (see Figs. 1, 2, 3, 4, 5 and 6). Therefore, the patient was finally diagnosed with multiple tuberculosis infections throughout the body and adrenal tuberculosis complicated with chronic adrenal cortex insufficiency, which caused severe hyperkalemia and hyponatremia, leading to cardiac arrest.

In the EICU, the patient was given mild hypothermia, a ventilator to assist breathing, and hormone replacement therapy, to correct his electrolyte imbalance. Because the velocity time integral (VTI) of aortic flow was too low, the patient was also treated with intra-aortic balloon counterpulsation (IABP). As the blood pressure increased, we gradually reduced the dose of vasoactive drugs. After $187 \mathrm{~h}$ of ECMO, the heart function recovered, and the myocardial electrical activity stabilized. In the end, the patient successfully left the EICU for further rehabilitation and was transferred to the infectious disease specialist hospital for standardized anti-tuberculosis treatment.

\section{Discussion and conclusion}

TB is one of the common infectious diseases in our country, among which lung tuberculosis is the most common, but TB bacteria can also invade many organs throughout the body, including the brain, spine, adrenal glands, and the pericardium, resulting in extrapulmonary TB. TB rarely causes acute and critical illness and

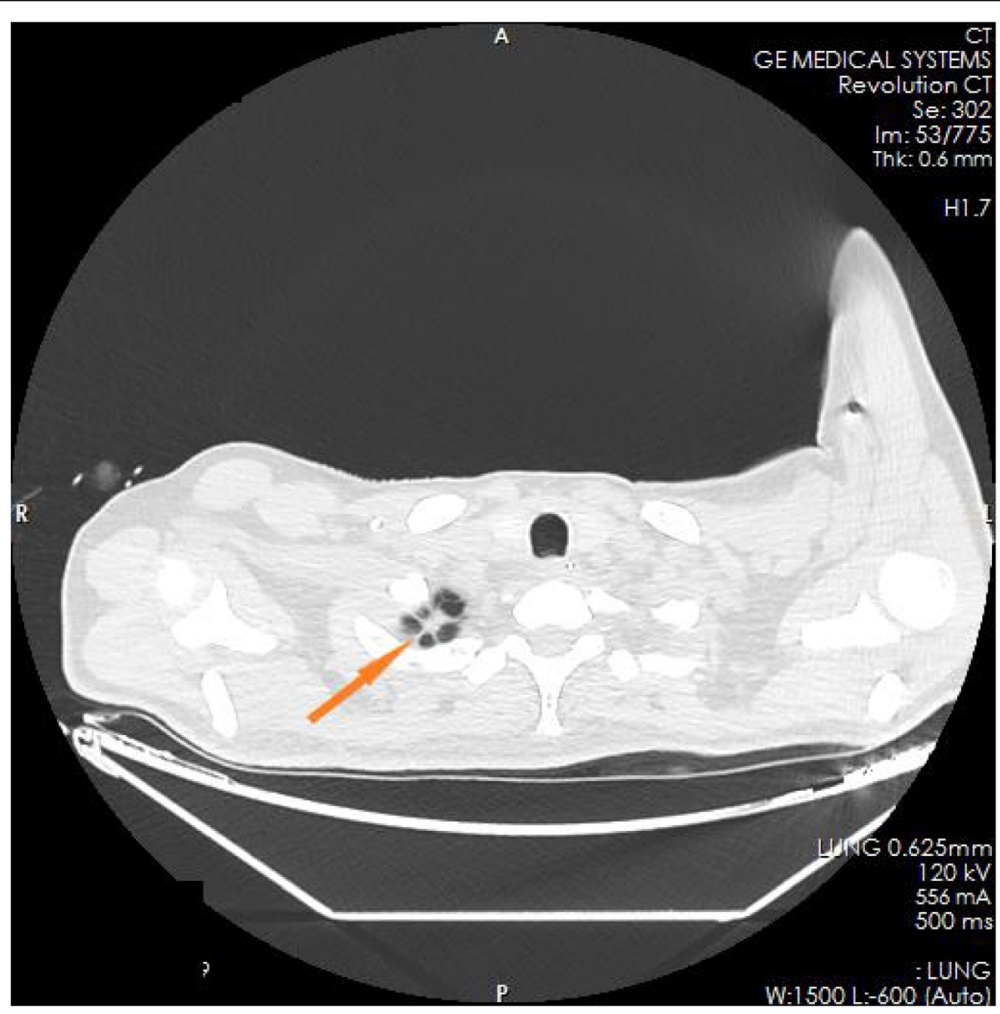

Fig. 1 CT pictures displaying multiple tuberculosis lesions throughout the body 


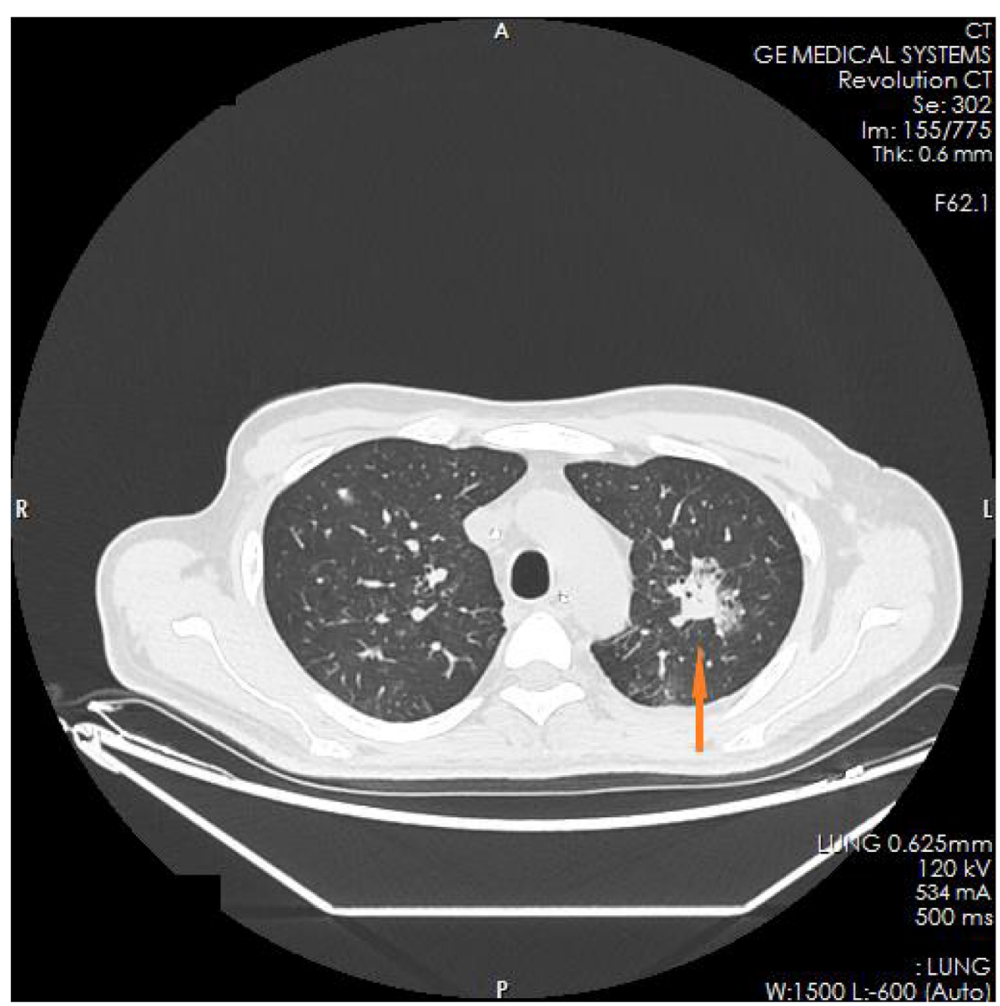

Fig. 2 CT pictures displaying multiple tuberculosis lesions throughout the body

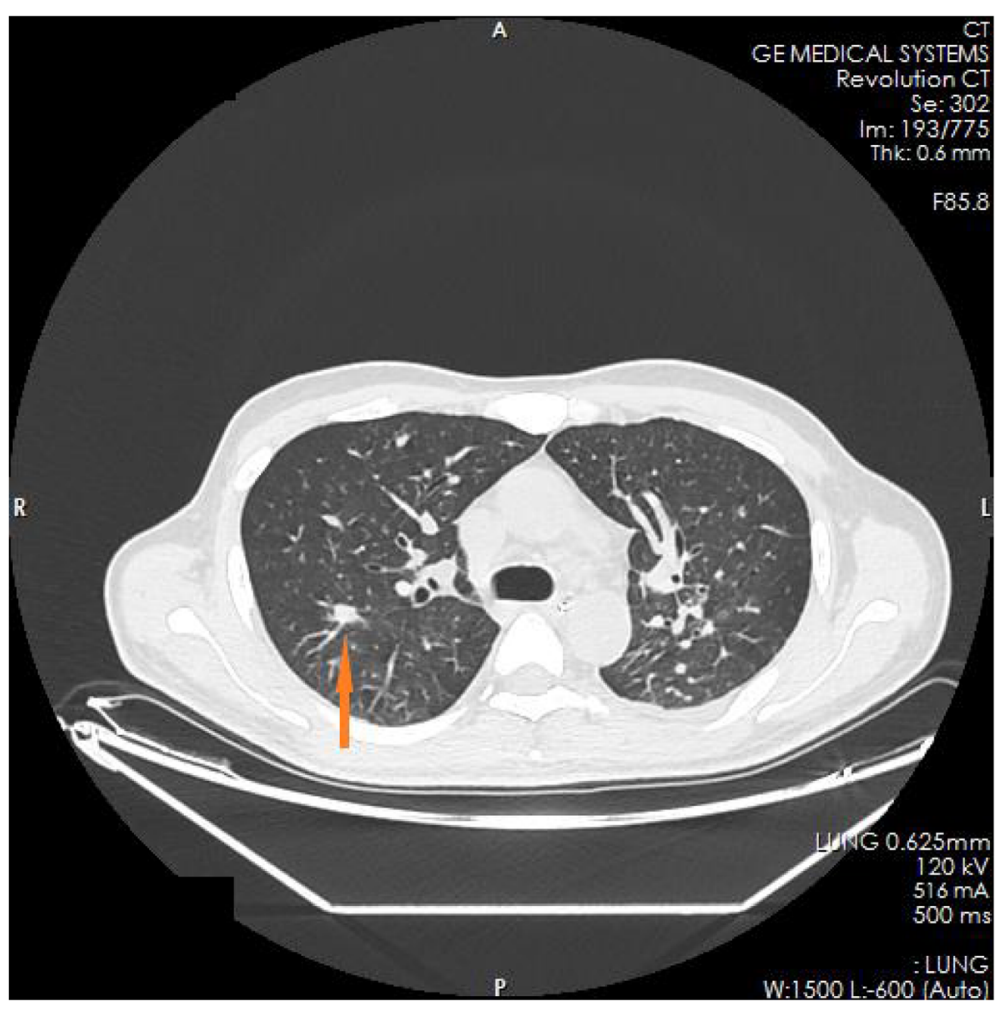

Fig. 3 CT pictures displaying multiple tuberculosis lesions throughout the body 


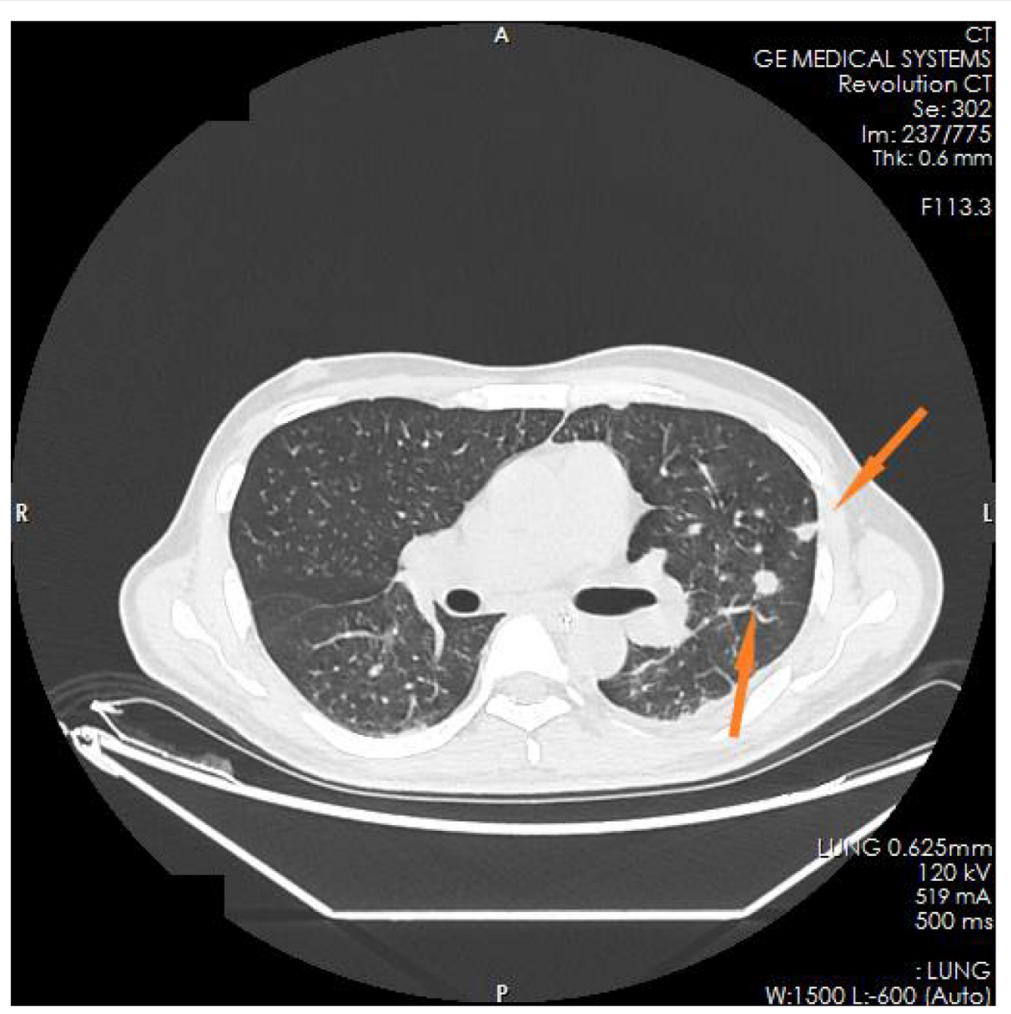

Fig. 4 CT pictures displaying multiple tuberculosis lesions throughout the body

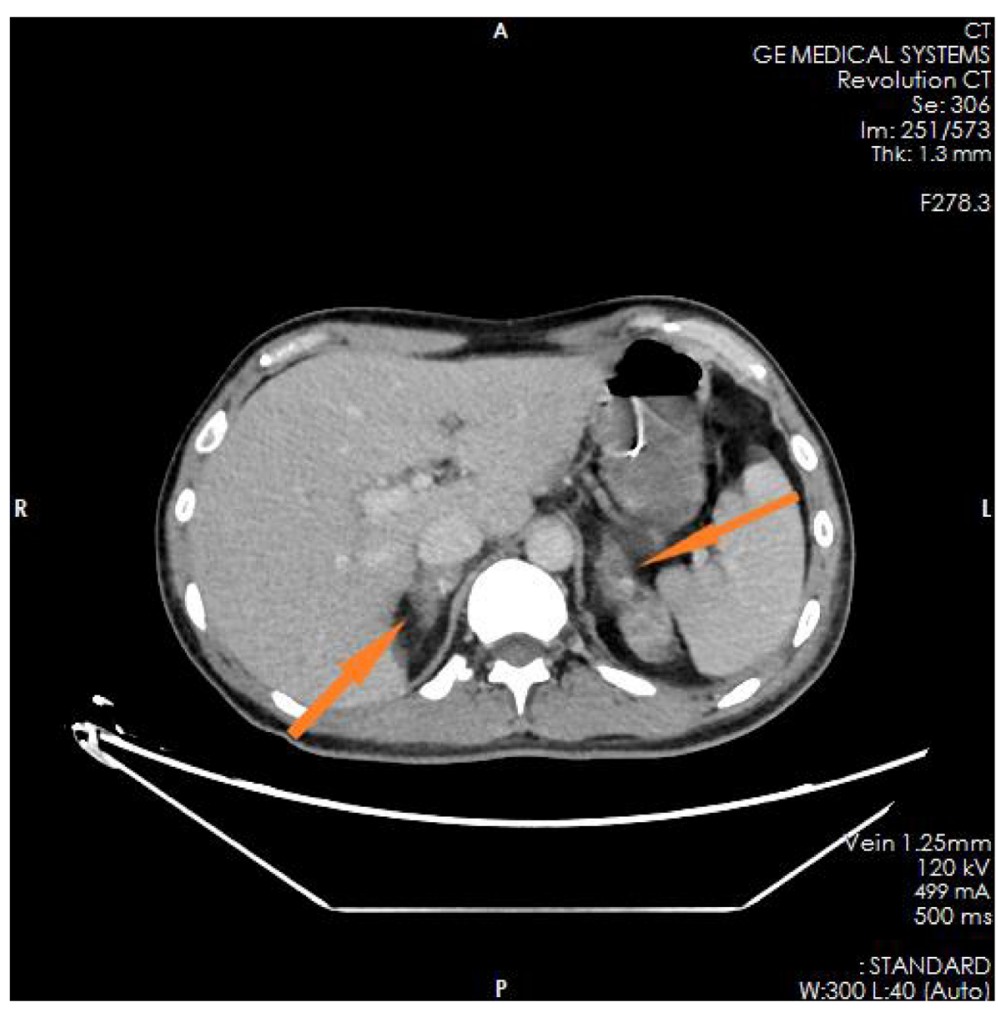

Fig. 5 CT pictures displaying multiple tuberculosis lesions throughout the body 


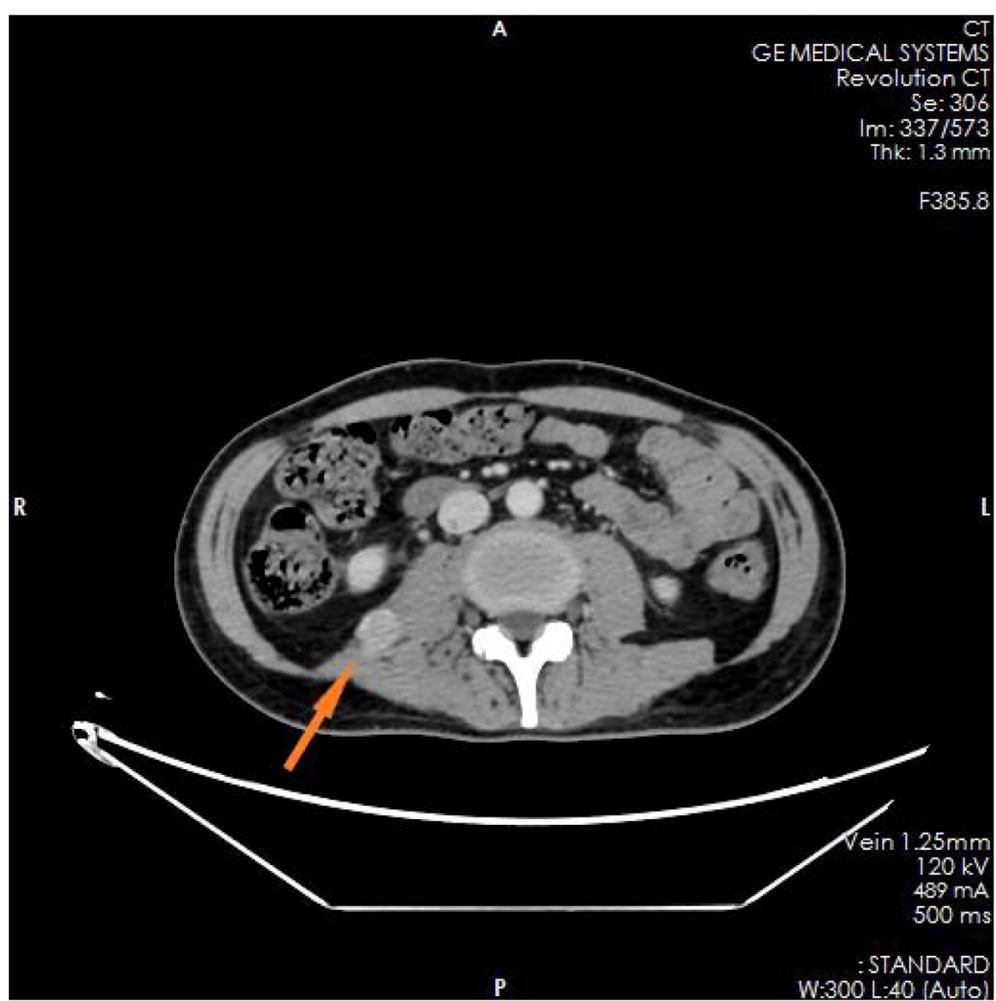

Fig. 6 CT pictures displaying multiple tuberculosis lesions throughout the body

usually has a chronic onset [1]. Unlike for this case, it is not common for TB patients to present to the ED with sudden cardiac arrest. Adrenal TB is one of the main causes of chronic adrenal insufficiency. The patient in this case had no typical clinical symptoms of TB, so early diagnosis and treatment were difficult. Therefore, patients with no typical TB symptoms should also be sufficiently cared for, and actively screened, and physicians should expand the scope of examination to avoid the emergence of severe conditions.

It is well known that a common cause of cardiac arrest is hyperkalemia, which itself have many causes. Primary adrenal insufficiency can cause a decrease in the secretion of aldosterone, which is a type of hormone that can simultaneously increase blood sodium levels and reduce blood potassium levels. Therefore, when the level of aldosterone is insufficient, it can cause refractory hyponatremia and hyperkalemia. Chronic adrenal insufficiency often has an insidious onset, mainly manifested by longterm poor appetite, nausea and vomiting, and fatigue [2]. These atypical symptoms make early diagnosis difficult. The patient did not have a systematic examination in time after he developed the symptoms, which eventually led to the deterioration of his condition.

ECMO is a new form of a mechanical cardiopulmonary life-support system. It involves the use of an artificial pump to transport nonoxygenated blood to a gas exchange device (oxygenator), where the blood is fully oxygenated and carbon dioxide is removed, after which the blood is reinfused back into the patient's circulation. ECMO can partially assist the patient's cardiopulmonary function [3].

Current research indicates that the application of VAECMO in the ED results in good outcomes for patients with cardiac arrest requiring prolonged CPR to recover spontaneous circulation and treat refractory cardiogenic shock. ECMO plays a role as a bridge, helping provide more opportunities for the diagnosis and treatment of critically ill patients with heart and lung failure [4]. When stable hemodynamics and adequate tissue oxygen supply are ensured for the patient, physicians have more time to actively search for the cause and treat the original disease.

Therefore, ECMO can be applied in the ED to patients with cardiac arrest of different etiologies, such as acute poisoning, internal environment disturbance, and severe infection, and for patients for whom conventional CPR has difficulty stabilizing their hemodynamics. The effects of ECMO are optimal for patients between 18 and 75 years old without any irreversible end-stage conditions. Patients with reversible neurological function should be given priority to receive ECMO [5].

However, there is still much work to be done regarding the use of ECMO in the ED. High-quality 
prospective randomized controlled studies are needed to further evaluate the benefits and drawbacks of this procedure. More evidence-based information is needed to formulate normative guidelines. Finally, an emergency ECMO team must be established for day and night services and continuous training should be carried out for ECMO team members.

\section{Abbreviations}

ECMO: Extracorporeal membrane oxygenation; ED: Emergency department; TB: Tuberculosis; CPR: Cardiopulmonary resuscitation;

ACTH: Adrenocorticotropin; ALD: Aldosterone; VTI: Velocity time integral; IABP: Intra-aortic balloon counterpulsation; CA: Cardiac arrest

\section{Acknowledgements}

All ECMO team members who actively participated in providing healthcare for that patient should be fully acknowledged.

\section{Authors' contributions}

ZLP, MXY, and WP are responsible for the treatment and management of this patient. HGQ is responsible for the data collection. YN is responsible for paper writing. All authors have read and approved the manuscript.

\section{Funding}

There are no special funders for this research.

Availability of data and materials

All data relevant to the study are included in the article.

\section{Declarations}

Ethics approval and consent to participate

This is just case report. Not applicable.

\section{Consent for publication}

Written informed consent was obtained from the patient for publication of this case report and any accompanying images. A copy of the written consent is available for review by the Editor-in-Chief of this journal.

\section{Competing interests}

There are no competing interests for any author.

Received: 1 August 2021 Accepted: 3 September 2021

Published online: 20 September 2021

\section{References}

1. Floyd K, Glaziou P, Zumla A, Raviglione M. The global tuberculosis epidemic and progress in care, prevention, and research: an overview in year 3 of the End TB era. Lancet Respir Med. 2018;6(4):299-314. https://doi.org/10.1016/ S2213-2600(18)30057-2

2. Hahner S. Acute adrenal crisis and mortality in adrenal insufficiency: still a concern in 2018. Ann Endocrinol (Paris). 2018;79(3):164-6. https://doi.org/1 0.1016/j.ando.2018.04.015.

3. Badulak JH, Shinar Z. Extracorporeal membrane oxygenation in the emergency department. Emerg Med Clin North Am. 2020;38(4):945-59. https://doi.org/10.1016/j.emc.2020.06.015.

4. Mosier JM, Kelsey M, Raz Y, Gunnerson KJ, Meyer R, Hypes CD, et al. Extracorporeal membrane oxygenation (ECMO) for critically ill adults in the emergency department: history, current applications, and future directions. Crit Care. 2015;19(1):431. https://doi.org/10.1186/s13054-015-1155-7.

5. Tonna JE, Selzman CH, Mallin MP, Smith BR, Youngquist ST, Koliopoulou A et al. Development and implementation of a comprehensive, multidisciplinary emergency department extracorporeal membrane oxygenation program. Ann Emerg Med. 2017;70(1):32-40. https://doi.org/1 0.1016/j.annemergmed.2016.10.001

\section{Publisher's Note}

Springer Nature remains neutral with regard to jurisdictional claims in published maps and institutional affiliations.

Ready to submit your research? Choose BMC and benefit from:

- fast, convenient online submission

- thorough peer review by experienced researchers in your field

- rapid publication on acceptance

- support for research data, including large and complex data types

- gold Open Access which fosters wider collaboration and increased citations

- maximum visibility for your research: over $100 \mathrm{M}$ website views per year

At $\mathrm{BMC}$, research is always in progress.

Learn more biomedcentral.com/submissions 